\title{
A REVIEW STRATEGIES INTEGRATING MS ISO 31000:2010 RISK MANAGEMENT PROCESS INTO PROJECT LIFECYCLE FOR MALAYSIA LANDSCAPE PROJECT ORGANISATION
}

\author{
Adam Aruldewan S.Muthuveeran*1, Osman Mohd Tahir², Roziya Ibrahim³, Saipol Bari Abd Karim ${ }^{4}$, Elly \\ Widiyanty Rasidin 5 \\ 1,2,3 Department of Landscape Architecture, Faculty of Design and Architecture, Universiti Putra Malaysia, Serdang, \\ Malaysia \\ ${ }^{4}$ Department of Quantity Surveying, Faculty of Built Environment, University of Malaya, Kuala Lumpur, \\ Malaysia \\ ${ }^{5}$ Faculty of Architecture, Planning \& Surveying Universiti Teknologi MARA, Shah Alam, Malaysia
}

E-mail: *aruldewan@yahoo.com

\begin{abstract}
Landscape projects in Malaysia have been facing prevailing issues with impact on project performance. These issues could be anticipated and addressed at an earlier stage by implementing effective risk management system. From previous studies on risk management system implementation into construction project as suggested by various studies show that there is no formal risk management system and integration of risk management process into a landscape project lifecycles. Considering this explorative potentiality within the gap, this study attempts to advance a conceptual framework by integrating the risk management process into a landscape project lifecycles. The conceptual framework is based on extensive reviews of related literatures in the variables but extensively covers two areas namely; MS ISO31000:2010 risk management process (RMP) and landscape project lifecycle (PLC) in developing the conceptual framework. A hypothetical framework for landscape project risk management process is then produced from the study and is surmise beneficial to enhance the understanding and application of risk management among landscape professionals for managing risk in Malaysia landscape development.
\end{abstract}

Keywords : Risk Management Process (RMP), Project Lifecycles (PLC), ISO 31000

\section{INTRODUCTION}

Landscape projects in Malaysia are exposed to a higher degree of risk and face a significant amount of uncertainties. The landscape construction projects are often faced with several challenges and issues; namely insufficient manpower, insufficient skills and expertise, insufficient knowledge, insufficient budget, lack of interest as well as of proper tools and equipment, poor quality of planting materials, insufficient landscape personal training and poor civil awareness and attitude (Antrop, 2005; Hussain \& Byrd, 2012; Hussein, 2014; Ibrahim, Rahman, \& Tahir, 2009; Jansson \& Lindgren, 2012; Osman Mohd Tahir, 2005) from various aspect putting landscape organisations to litigation risks and to a possible organization's downfall (Capouya, Compton, Dantzler, \& Howard, 2012; Godi \& Sibelius, 2012). Landscape projects face greater risks as liability increases in today's industrial complexity due to landscape architect's bigger roles in certain projects, increase of project scope, society becoming more aware of their litigious rights, changes in contract system and higher expectation by clients (Gilmartin, 2016; Godi \& Sibelius, 2012).

A systematic management like Project Risk Management (PRM) is needed in managing a landscape project risk to ensure the risk owner possess a sufficient knowledge in this particular discourse in order to successfully conduct risk management process. A project risk management is beneficial for projects to enhance project performance through precise systematic management of project risks (Cooper, Grey, Raymond, \& Walker, 2005; Hillson, Grimaldi, \& Rafele, 2006; Ward \& Chapman, 2003) and has since been integrated as part of the project management process (APM, 2012; PMI, 2017). Several studies of PRM benefits by Abdul-Rahman, Wang, 
\& Sheik Mohamad (2015); Jusoff, Yusuwan, Adnan, \& Omar (2008); Kang, Fazlie, Goh, Song, \& Zhang (2015); Mills (2007); PMI (2017); and Ward \& Chapman (2003) provide an understanding of the risk management application in projects have been reviewed to improve chances of reaching project performance objectives and provide better control over the future outcome of the project. However, further study is carried out by Adnan (2008); Goh \& Abdul-Rahman (2013); Hamzah Abdul-Rahman, Chen Wang (2015); Jusoff, Yusuwan, et al. (2008); Kang et al. (2015); and Mohamed, Abd-Karim, Roslan, Mohd Danuri, \& Zakaria (2014) in the attempt to guide towards understanding and practicing PRM in Malaysia in the context of construction. Furthermore, studies' observation revealed that in Malaysia, there is seldom to no formal risk management applied in landscape project even when there is a risk management standard like Malaysia Standard MS ISO 31000:2010. Although various risk management system guide and standard provided, the shortcoming prevail that how and when to PRM to project practice; specifically there is a lack of special studies on standard structures to integrate RMP into landscape PLC.

Therefore, this study attempts to respond to this need by proposing a conceptual framework by integrating MS ISO 31000:2010 RMP into Malaysia landscape PLC. This framework will provide a potential solution to bridge the gap between the current project issues and the ideal project outcome within the context of managing risks systematically. The developed framework will be guidelines for landscape organisations to manage risk systematically and proactively throughout the project lifecycle for enhancement of project performance and to minimise the project risk. This will safeguard project practitioners from being impacted by project issues and further enhancing landscape outcome.

\section{LITERATURE REVIEW}

\subsection{Malaysia's Landscape Issues and Challenges}

This study attempts to relate the landscape management issues and challenges that arises with the failure in managing risks during project lifecycle at the very beginning that consequently impact project outcome. Studies show there is various issues and challenges in the landscape industry across different country and places and that the degree of issues differ from geographical location but somehow interrelated and need further attention (Osman Mohd Tahir, 2005). According to Osman Mohd Tahir (2005), in Malaysia common landscape issues namely insufficiency; in manpower, skills as well as expertise, knowledge, budget, lack of interest, lack of proper tools and equipment, poor quality of planting materials, insufficient landscape personal training and poor civil awareness and attitude. (Abdul Malek \& Mariapan, 2009; Hussain \& Byrd, 2012; Hussein, 2014; Ibrahim, 2016; Ibrahim et al., 2009; Jansson \& Lindgren, 2012) further revealed issues and challenges in urban landscape prevails such as lack of management and maintenance aspect, insufficient political support, funding and awareness, insufficient professionals and skilled manpower, poor planning and design and lastly issues in safety and vandalism. The issues and challenges in landscape create poor landscape outcome that will lead to greater liability of consequences to landscape practitioners.

\subsection{Managing Risk In Malaysia's Landscape Project}

With systematic risk management in place, it will ideally improve project performance (Ward \& Chapman, 2003) via the systematic risk management process of identifying, analysing and treatment in order to achieve project objectives (PMI, 2017). The integration of risk management system is vital in current landscape project management process by adapting from suitable risk management standards already available in the industry for instance MS ISO 31000:2010's standard. MS ISO 31000:2010 standard has various range of applications on various industry where it can be applied in construction activity, design and product liability as well as environmental issues, human, flora and fauna's wellbeing, occupational safety and health, operational system, maintenance systems, procurement system, project management, public risk and general liability. This much related activities often takes place in Malaysia's landscape organisation whereby due to landscape construction's dynamism and complexity by nature, it is prone to various project risks (HB 436:2004, 2005; MS ISO 31000:2010, 2010). According to Goh \& Abdul-Rahman (2013), different risk arise in different stages in construction. They added that during the initial stage of a project, higher level of uncertainties would generate higher risk contributing towards higher costs comparative to other stages of the project's timeline. The absence of project information and data at the initial stage of a project prompts a higher level of risk related with quality, cost and time. This will continue on by frequent rising of risks during the construction stage of a project. Hence, risks should be forecasted and managed at an early stage to enable the organisation to take necessary actions to avoid it 
from happening or reduce the risk consequences (Mohamed et al., 2014). Under traditional procurement direction, the landscape architect that taking roles as lead designer in landscaping project has to ensure that all risks related to design works are properly managed and controlled. However, according to Jusoff, Rashid, \& Adnan (2008), a proper management of risks vary from different organisations and are commonly not structured or formatted especially in managing design related risk in a landscape architectural practice.

Furthermore, Malaysia's landscape practitioners often do not practice a comprehensive risk management but are dependant solely on contractual agreement and transfer to other parties by way of risk avoidance. From reviews and interviews it reveals that the biggest challenge in implementing risk management in Malaysia is that there is no formal risk management guidelines and standard to be applied to in Malaysia's landscape sector. Risks are often not managed carefully and do not follow the structured procedures due to lack of knowledge of risk management and its implementation, besides lack of awareness of its benefits. There is also no clear framework on the strategies to integrate risk management into the project lifecycle course or innovated in the current Malaysian landscape industry.

\subsection{Landscape Project Lifecycle (PLC)}

A PLC according to (APM, 2012) is a collection of generally sequential, time-based, project phases whose name and numbers are determined by the control needs of the organization involved in the project. PLC differs across the various industries and businesses (APM, 2012; BS 6079-1:2010, 2010). Due to the complex and diverse nature of the project, there is no agreement among industries or even between organizations within the same industry on lifecycle phases (Kerzner, 2009). There is no specific standard of project lifecycles but each own organization defines their own project lifecycles phases and decide on their own point of phase demarcation in align to business process and methods (Lester, 2003). This study look onto various organisation scope to seek common stand on PLC namely; project management, construction industry and landscape architecture.

In project management, according to PMI (2017), a typical project can be mapped to four generic phases of project life cycle structure; starting the project, organizing and preparing, carrying out the work, and closing the project. Similarly, APM (2012) had divided a project life cycle into four stages; concept, definition, development and handover and closure, and extended to two stages; benefits realization and operation. Meanwhile, BS 60791:2010 (2010) and Lester (2003) define PLC to five stages; conception, feasibility, implementation, operation and termination. Project management author, Kerzner (2009) define PLC to five stages; Conceptual, Planning, Testing, Implementation and Closure. Generally, according to BS 6079-1:2010 (2010) PLC comprise two to six phases and seldom more than ten.

In construction industry aspect, amalgamation perspective on PLC from several author; Bennet (2003), Gould \& Joyce (2009), Gray \& Hughes (2001), Hackett, Robinson, \& Statham (2007), Levy (2010) and Turner (2009), summarize that PLC may and may not be consecutive consist of five phases namely conceptual phase, design phase, procurement phase, construction phase and commissioning phase.

Landscape project management organisation, in extension from project management and construction industry above define PLC into various aspect. Zubir (2015) divided the landscape project cycle in Malaysia into nine stages; definition, planning, concept design, schematic design, detail design development, pre-tender \& tender, construction, defects liability period (DLP) \& maintenance period and lastly, handover. (Holmes, 2017) define PLC to nine stages; project inception \& initiation, concept design, design development (detailed design), construction documentation, tendering (procurement), construction, construction management (construction administration) and lastly, maintenance. In landscape management project aspect, (CEP-CDPATEP, 2011) has broken down the project to five stages; initial hypothesis and territorial vision, reconnaissance and diagnosis, proposal formulation, development and implementation and lastly; dissemination and then the follow-up.

Amalgamation from project management, construction industry and landscape architecture PLC process, this study produce a PLC to suit Malaysia's landscape project scenario that is divided into four stages; initiating, planning, executing and closing, with further divided to seven phases as illustrated in Figure 1. 


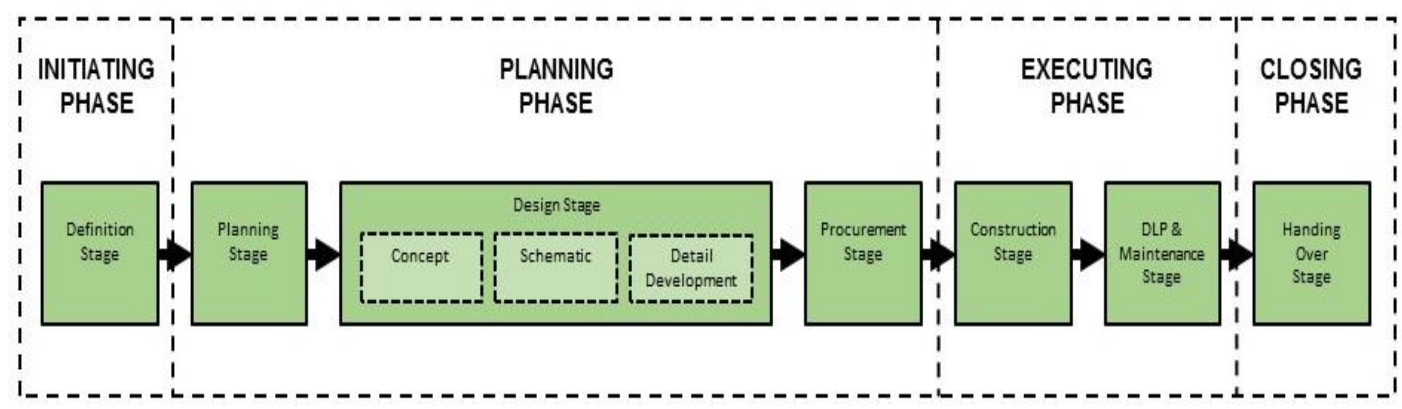

Figure 1: Landscape PLC

\subsection{MS ISO 31000:2010 Risk Management - Principles and Guidelines}

International Organization for Standardization (ISO) has developed several standards and guidelines relating to risk management. ISO 31000:2009 standard has prescribed that associations to create, actualize and persistently enhance a structure whose reason for existing is to coordinate the procedure for overseeing risk into the association's general administration, technique and arranging, management, announcing forms, arrangements, qualities and culture. The generic approach explained in this standard gives the standards and rules to dealing with any type of risk in a systematic, transparent and credible manner to required context and scope (BS ISO 31000:2009, 2009). In Malaysia, an identical standard with ISO 31000:2009, MS ISO 31000:2010 Risk Management - Principles and Guidelines is recommended, published and adopt Technical Committee on Risk Management govern by Industry Standards Committee on Organisational Management (ISCO) to cater to the country needs (MS ISO 31000:2010, 2010).

\subsubsection{The Scope of MS ISO 31000:2010}

The MS ISO 31000:2010 standard is not limited to any specific sector and industry as it can be utilized by any public, private or community enterprises, association, group or individual entity. The standard can be applied to a wide range and throughout the life of an organisation trade and activities namely organisation strategic planning, corporate decision making, operational, processes, functions, projects, products, services and assets. It's also applied in any type of risk, either to positive or negative outcome risk. Despite the fact that it offers generic guidelines, the standard plans to embed risk management process into existing and future organization process in managing risk rather promote consistency of risk management across organizations. It gives a common approach in support to managing standards of particular risks or sector and does not supplant those measures (MS ISO 31000:2010, 2010)

Generally, the standard consist of three components which are; Clause 3: Risk Management Principles, Clause 4: Risk Management Framework and Clause 5: Risk Management Process. The relationship between these three risk management components are described in this MS ISO 31000:2010 standard in Figure 2. 


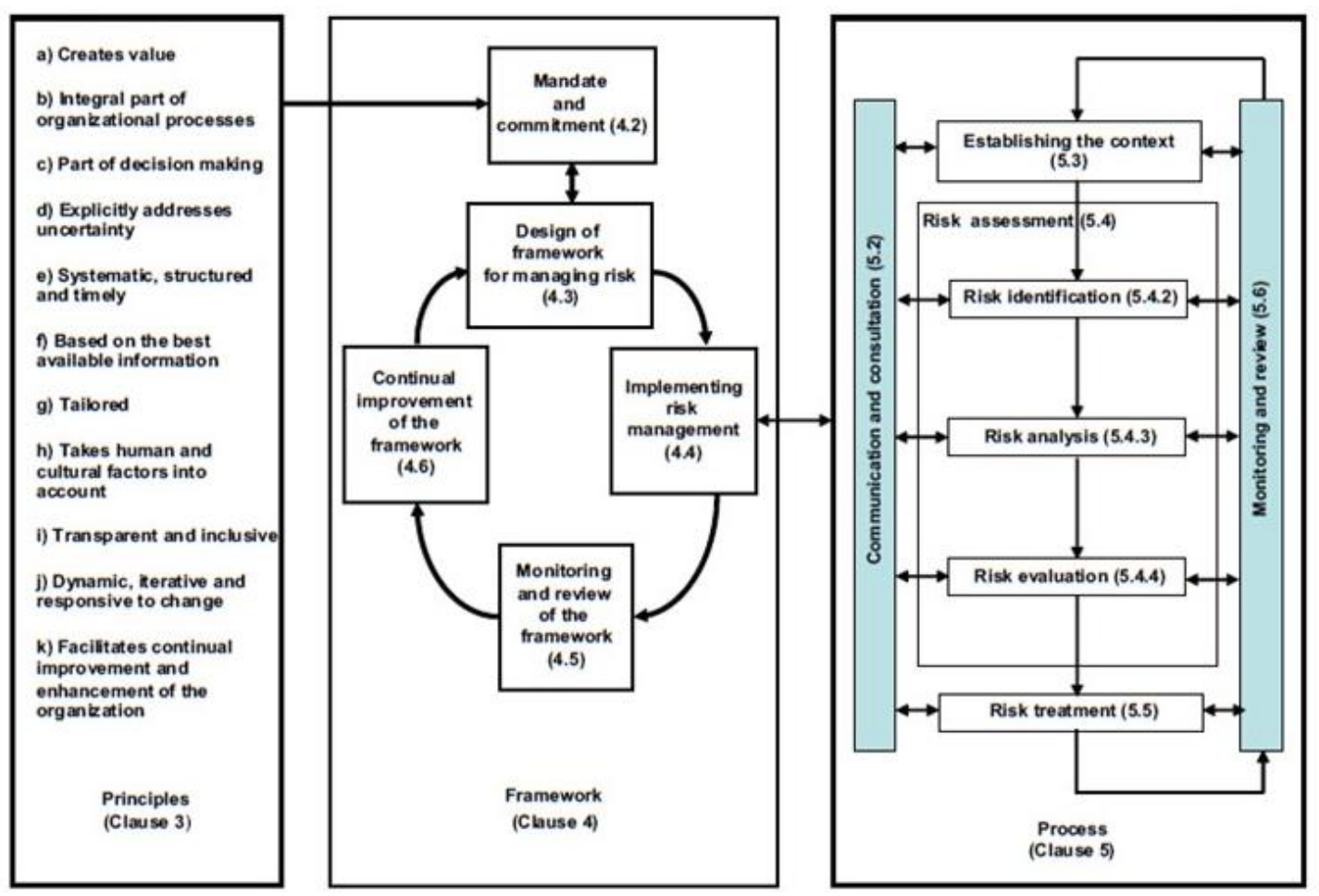

Figure 2: MS ISO 31000:2010 Risk Management Principles, Framework and Process Relationships Source from MS ISO 31000:2010 (2010, p. viii)

\subsubsection{The Risk Management Process (RMP)}

The third standard component; RMP are placed as an integral part of the management and is integrated to suit the organisation's culture and custom fitted to the organisation's business processes. In this study, the risk management process will be imbedded into landscape project management lifecycle, similar to several studies proposed by other researchers (Chapman \& Ward, 2003; Prieto Ibáñez, Macías Bernal, Chávez de Diego, \& Alejandre Sánchez, 2016; Sousa, Almeida, \& Dias, 2012). The MS ISO 31000:2010 standard summarizes risk management into seven process area, described in Table 1.

Table 1: RMP Descriptions

Source from De Oliveira, Marins, Rocha, \& Salomon (2017); MS ISO 31000:2010 (2010); and Purdy (2010)

\begin{tabular}{|l|l|}
\hline \multicolumn{1}{|c|}{ RMP } & \multicolumn{1}{c|}{ Description } \\
\hline $\begin{array}{l}\text { Communication and } \\
\text { consultation }\end{array}$ & $\begin{array}{l}\text { Spreads the presence of plans for communication among the gatherings in charge } \\
\text { of actualizing the risk management process and the invested individuals. It is a } \\
\text { significant advance since its motivation is to guarantee that every one of those } \\
\text { associated with the procedure comprehend the grounds on which choices will be } \\
\text { made and the reasons why particular activities are required. It is additionally } \\
\text { critical to comprehend partners' targets, with the goal that their association can be } \\
\text { arranged and their perspectives can be considered in setting risk criteria. }\end{array}$ \\
\hline Establishing the context & $\begin{array}{l}\text { Includes whether the firm explains its destinations, characterizes the external and } \\
\text { internal parameters that will be considered in overseeing risks and sets up the } \\
\text { degree and risk criteria for whatever remains of the procedure. }\end{array}$ \\
\hline Risk identification & $\begin{array}{l}\text { Intends to create an exhaustive rundown of risks from various sources, the } \\
\text { occasions, their causes and potential results, and the territories influenced. Risk } \\
\text { identification requires the use of a precise procedure to comprehend what could } \\
\text { happen, how, when, and why. }\end{array}$ \\
\hline Risk analysis & $\begin{array}{l}\text { Plans to give a comprehension of risk to fill in as the reason for settling on } \\
\text { choices on the best methodologies and strategies to manage them. Risk analysis } \\
\text { includes thought of the causes and wellsprings of risks, their negative results and }\end{array}$ \\
\hline \hline
\end{tabular}




\begin{tabular}{|c|c|}
\hline & $\begin{array}{l}\text { the likelihood these outcomes will happen. Risk analysis can be embraced with } \\
\text { changing degrees of detail, contingent upon the risk, the reason for the analysis, } \\
\text { and the data, information, and assets accessible. Analysis can be qualitative, } \\
\text { semi-quantitative, quantitative, or a blend of these, contingent upon the } \\
\text { conditions. }\end{array}$ \\
\hline Risk evaluation & $\begin{array}{l}\text { To give more help to deciding, in light of the aftereffects of the risk } \\
\text { investigation, by assessing what risks require treatment and the need of } \\
\text { actualizing that treatment. Includes settling on a choice about the level of risk } \\
\text { and the need for consideration through the use of the criteria created when the } \\
\text { setting was built up. }\end{array}$ \\
\hline Risk treatment & $\begin{array}{l}\text { Involves the choice of at least one alternatives to adjust the risks and the } \\
\text { execution of these choices, Through a recurrent procedure that investigations the } \\
\text { treatments already connected, leftover risk levels, usage of another treatment for } \\
\text { deplorable remaining risks and assessment of the adequacy of the treatment } \\
\text { proposed. }\end{array}$ \\
\hline Monitoring and review & $\begin{array}{l}\text { Monitoring and basic review ought to be arranged as a feature of the risk } \\
\text { management process, to plainly characterize duties among those included, } \\
\text { covering all parts of the risk management process. Fitting activity happens as } \\
\text { new risks rise and existing risks change because of changes in either the } \\
\text { association's destinations or the inward and outside condition in which they are } \\
\text { sought after. This includes natural examining by risk proprietors, control } \\
\text { affirmation, accepting new data that ends up plainly accessible, and learning } \\
\text { lessons about risks and controls from the examination of victories and } \\
\text { disappointments. }\end{array}$ \\
\hline
\end{tabular}

\section{METHODOLOGY}

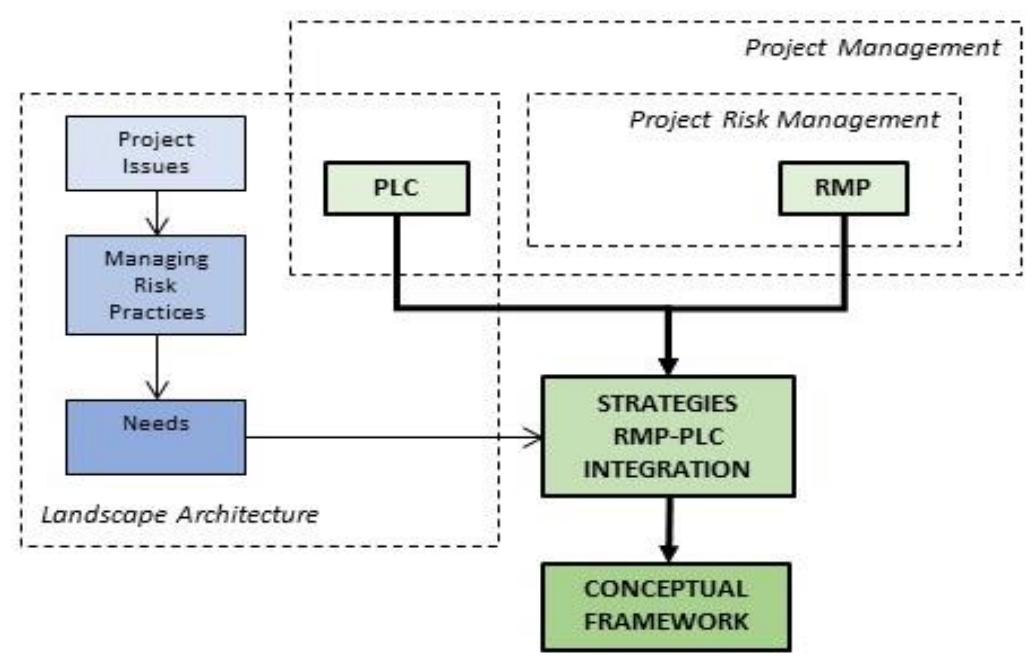

Figure 3: Theoretical Framework

This study aims to develop an RMP integration into PLC strategies and conceptual framework for landscape project organisation's use. The study began with a review of landscape project issues and current managing risks faced by practitioners in landscape project organisation. By conducting systematic literature review, a need of strategies to integrate RMP into PLC is identified to resolve the issues reviewed earlier. As suggested by Sekaran (2003) and (Merriam, 2009), a process theoretical framework is initiated, based on extensive reviews of related literatures in the variables however the research extensively covers two areas namely; MS ISO31000:2010 RMP and PLC. The conceptual framework in integrating RMP to PLC is develop based on theoretical framework that illustrated in Figure 3 above. 


\section{STRATEGIES INTEGRATING MS ISO 31000:2010 RISK MANAGEMENT PROCESS (RMP) TO LANDSCAPE PROJECT LIFECYCLE (PLC)}

\subsection{Review of Strategies Integration RMP to PLC}

Several authors and standards attempt to integrate RMP into PLC process. According to (PMI, 2017), RMP is divided into nine phases; plan risk management, identify risks, perform qualitative risk analysis, perform quantitative risk analysis, plan risk responses, implement risk responses and monitor risks. During PLC, the planning of risk management is suggested to be performed at the starting of project PLC which is the project initiation stage. Once the project enters the planning stage, where sufficient project information is gathered; risk identification, qualitative and quantitative risk analysis and risk responses will be performed in sequence. Implementation of risk responses is suggest to be done during the project execution stage. Whereas, the monitoring of risks performances are done throughout whole PLC phase (Kerzner, 2009; PMI, 2017).

APM (2010) assert the simplest description of the RMP consists of five phases; initiate, identify, asses, plan responses and implement responses, together with a managing the process. According to APM (2010), RMP is suggested to be carried out as earliest during PLC initiation stage where all five RMP phases are performed to complete the first cycle, ideally before significant commitments are made and should continue in an appropriate form throughout the project life cycle. The continuum of RMP should be performed to second and third cycle. The three RMP cycle is known as strategic-level risk management cycles which then moves to tactical-level, which is the risk management performance iteractively and managed throughout PLC process. In support of the APM (2010) RMP integration to PLC, Chapman \& Ward (2003) suggested the three strategic-risk management cycle to be initiated as earliest of the PLC initiation stage and to be completed by the end of PLC planning stage. It then follows the implementation of risk responses intensively to the rest of PLC stage, while risks are managed at the start of PLC executing stage.

Meanwhile MS ISO 31000:2010 (2010) explained that the typical RMP are theoretically performed in sequence throughout PLC to three phases; establish the context, assess risks and then treat the risks. Communication, consultation, monitoring and review should occur throughout PLC as the build-up communication and consultation with external and internal stakeholders take place earliest when an instance of the RMP is being designed, during PLC initiation stage (BS 31100:2011, 2011).Establishing the context process is done as well in parallel with communication and consultation process during PLC initiation stage. Meanwhile, risk assessment starting point is suggested by BS 31100:2011 (2011) to be done once all the project information is obtained during the PLC planning stage. According to IEC/FDIS 31010:2009(E) (2009), risk assessment can be applied at all stages of the life cycle and is usually applied many times with different levels of detail to assist in the decisions that need to be made at each phases. Risk treatment is a continual step after risk assessment is recognised while the risk treatment plan will be produced before continuing to the next phase of the landscape project. Implementation of risk treatment is then carried through to the remaining PLC stages and seek for residual risk that may arise from the remaining project process. Monitor and review is done continuously and encompass all aspects of the risk management process. This means; monitoring and reviewing applies to whole PLC stage. And finally, the entire RMP is recorded and finalized at the closing stage of PLC.

\subsection{RMP Preforming Period}

Arguments raised between scholars either when the best period to start to impose RMP in PLC. According to Kerzner $(2009$, p. 756), the degree of risks and uncertainty are greatest at the start of the project but eventually will decrease over PLC as project decision achieved and project delivered is accepted. Vice-versa, the cost of altering error and making changes increase substantially over project lifecycle towards completion. This signify that risk management is to be carried out as earliest possible of the project lifecycle, supported by Chapman \& Ward (2003), Kerzner (2009) and PMI (2017). The risk management process should be applied immediately at the start of the project, ideally before significant commitments are made and should continue in an appropriate form throughout the project life cycle (APM, 2010). Arguably, according to APM (2010) and Chapman \& Ward (2003), initiating RMP in a project before the plan stage is in general more difficult, because the project is more fluid and less well defined where documentation is hard to come by and alternative interpretations of what is involved may not be resolvable. Performing the RMP at PLC initiation stage will focus on the business case, project revenues and contractual strategies (APM, 2010). 
Meanwhile, performing RMP at the end of the PLC planning stage asserts more effective results observed by Chapman \& Ward (2003) as it is the easiest place to start for first-time users of an RMP. A fair amount of information about the project is available but scope for significant contributions of formal risk management to project performance observed. This is supported by APM (2010) that can focus the project on strategic design choices and strategic planning in terms of activity-based plans. In PMI (2017), there are twenty four project management processes in PLC planning stage from total of forty seven project management processes. This signify that during the planning process group, projects are more feasible with solid information of project and involvement of all stakeholders of a project is vital as their input is required in developing the risk management plan.

Performing RMP later than the PLC planning stage is generally thought to be too late and create several difficulties, where the benefits of adapting formal risk management could not be put to realisation. This is because, according to Chapman \& Ward (2003), the contracts are made, equipment has been purchased, commitments are in place, reputations are on the line and managing change is comparatively difficult and unrewarding. It will be very difficult to influence any strategic decisions (APM, 2010).

From review, the best possible period to initiate RMP is at the earliest PLC stage which is the strategicrisk management; to define the feasibility of the project in terms of business revenues and contractual strategies. This may not be necessary if the landscape project takes on the traditional procurement path compared to design \& build or management procurement where the project objectives are generally predetermined earlier. The second cycle of RMP is suggested to be performed during PLC planning stage when sufficient project information and its scope is established. Strategies in performing risk identification, analysing of risks and its evaluation is more visible and effective during this stage. The next RMP cycle continuous to each significant stage and it is an iterative process within PLC.

\subsection{A Conceptual Framework}

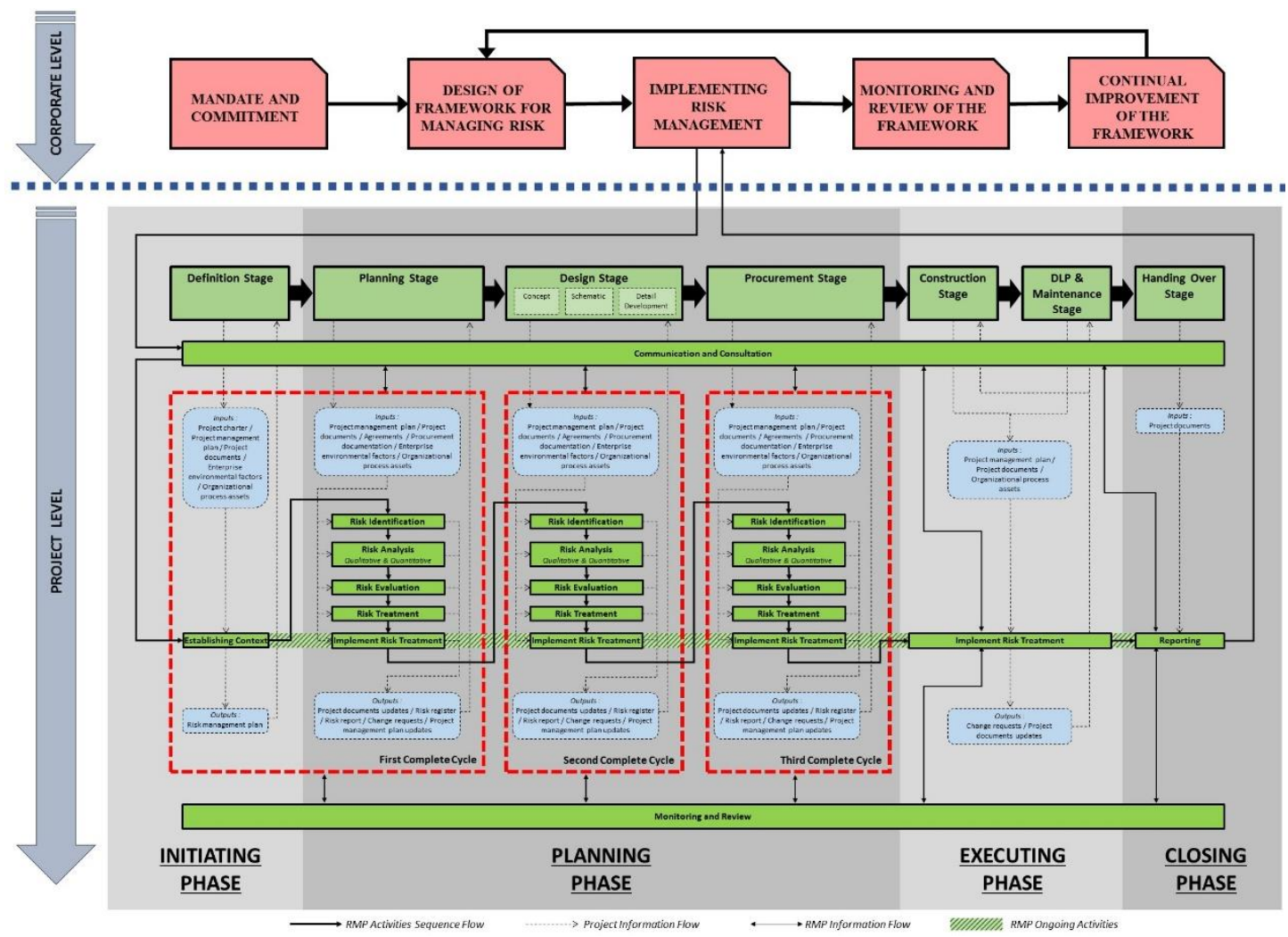

Figure 4: Conceptual Framework of Strategies to Integrate RMP into Landscape PLC 
According to (BS 31100:2011, 2011; ISO/TR 31004:2013(E), 2013), risk management framework should be developed at organisation level first before implementing the RMP. MS ISO 31000:2010 (2010) further added that organisations' risk management framework should be designed to ensure RMP information are adequately reported and used as basis for decision making and accountability at all relevant organizational levels. The RMP should be an integral part of management, embedded in the culture and practices and tailored to the business processes of the organization (MS ISO 31000:2010, 2010). In this study, the RMP tailored to the organisation process refers to the landscape project as its main operation business portfolio in the landscape organisation. The developed conceptual framework (refer to Figure 4) is demarcated into two levels; at the top is where the risk management framework is designed at the organisation level and at the project level is where it inter-relates the implementation of risk management framework procedures into landscape project lifecycles process is done. The success of RMP application depends on the effectiveness of the management's framework providing the base and coordination that embedded throughout the organization activities at all levels (MS ISO 31000:2010, 2010). The method described in this conceptual framework has been kept as simple as possible, while nevertheless fully encompassing all the various methods and viewpoints known to the authors that contribute to the comprehensive analysis and management of risk. This means that this conceptual framework does not knowingly exclude any approaches that are currently being used successfully.

\subsubsection{Organisation Level: Designing Organisation Risk Management Framework}

Organisation risk management framework to be initiated first at corporate level which the framework process will be implemented throughout organisation ongoing activities (BS 31100:2011, 2011).

The formulated framework to consider current operational practices, process, resources, system and culture within organisation context to enable effective risk management (ISO/TR 31004:2013(E), 2013). The process of managing risks start with designing organisation risk management framework at organisation level, as it consist Five (5) component within the framework of risk management. The first component, Mandate and Commitment; the risk owner to build up a solid foundation and maintained responsibility by management of the organization and in addition a key and thorough leadership intending to accomplish duty at all levels required in acknowledging successful risk management. The second component, Design of Framework for Managing Risk; whereby before initiating the design and the implementation of risk management framework, the risk owner has to understand the organization's context and objectives. Then, in designing the framework, the risk owner has to establish a risk management policy as a way to seek accountability to incorporate risk management practices into the organization procedures, to dispense fitting assets and to build up communication and reporting mechanisms for internal and externally. The third component, Implementing Risk Management; the designed risk management framework particular to the organization is then implemented by defining the right timing and framework implementation strategies, further apply the risk management policy and process to organisation procedures. It assures legal and regulatory compliance, ensure that decision making are in accordance to risk management process outcome. In this component, briefing and training sessions, stakeholder's consultation and stakeholder's communication are to be performed. The forth component, to Monitoring and Review of the Framework; is the part to ensure that the risk management to stay effective and continuously supportive in enhancing organisation's performance. Lastly, the fifth component, Continual Improvement of the Framework; the risk owner to assure for continual improvement in the organisation's framework in risk management and determining cultures based on risk management monitoring and reviews results (BS 31100:2011, 2011; IEC/FDIS 31010:2009(E), 2009; ISO/TR 31004:2013(E), 2013; ISO Guide 73:2009, 2009; MS ISO 31000:2010, 2010).

\subsubsection{Project Level: RMP Integration Into Landscape PLC}

During project level, the RMP that is integrated into landscape PLC as illustrated in the conceptual framework, is the extension from the third of the component of an organisation risk management's framework. Landscape projects predominate all the activities in a typical landscape architecture's organisation as it determines the survival of the organisation's portfolio. The dynamic and unique nature of projects create multiple project risks that needs to be managed to assure project objectives are achieved (Akintoye \& MacLeod, 1997; APM, 2012; Mills, 2007; Ng \& Loosemore, 2007; PMI, 2017), which by failure of doing so results to financial loss, affects organisation's reputation that could contribute to loss of business in the future (Algahtany, Alhammadi, \& Kashiwagi, 2016; Hamzah Abdul-Rahman, Chen Wang, 2015). Hence, the conceptual framework proposes for the RMP to be integrated into a landscape PLC procedure to assure that project risks are managed systematically. 
As illustrated in proposed conceptual framework, the PLC divided to four phases; initiating, planning, executing and closing. It further divided to seven stages; definition, planning, design, procurement, construction, DLP \& maintenance and handing over. The bold arrow line signify RMP sequence activities flow throughout PLC. The dotted arrow represent the project information flow from PLC as input to RMP activities and output back to PLC. The double arrow line represent RMP information flow interchangeably with communication $\&$ consultation and monitoring \& review process.

Before RMP is to be implemented, an effective communication and consultation both internal and externally are to be established by risk owner and the stakeholders to understand the basis of the decision making process. Communication and consultation are to be developed at definition stage and throughout all stages of the PLC. According to PMI (2017), intensity of risks are at the highest during the definition stage of the project and the cost of altering error and making changes subsequent to the risk incurred increases substantially over the PLC towards completion. Supported by APM (2012); Cooper et al. (2005); Hillson (2012); PMI (2017) and Ward \& Chapman (2003), furthering support that risk management process is to be carried out as earliest as possible and throughout the PLC.

During the PLC definition stage; establishing context process is to articulate project risk objectives, to define the external and internal parameters of responsibility at overseeing the project risk, and sets the degree and risk criteria for the rest of the procedure in more prominent detail and especially how they identify with the extent of the specific project (BS 31100:2011, 2011; ISO/TR 31004:2013(E), 2013; MS ISO 31000:2010, 2010)._This insertion of landscape project's common activities are to be done at this phase when the project is firstly registered as to develop project scope and review with client (APM, 2010; Chapman \& Ward, 2003). The information's input from project charter, project management plan, project documents, enterprise environmental factors and organizational process assets to enable risk context establishment. The output of risk management plan that describes how risk management activities will be structured and performed, back to PLC (PMI, 2017).

Most project management activities happened during PLC planning phase in landscape project organisation. This includes; project planning, conceptual design, schematic design, detail design development and procurement. Meanwhile, according to PMI (2017), out of forty seven project management processes identified in the PMBOK Guide that further groups these processes in ten separate knowledge areas, twenty four project management processes happened during PLC planning stage. This indicates that all project core control of quality, time, scope, organisation, information and even risk recourse allocations and decision making takes place during this stage (APM, 2012; PMI, 2017). Hence, as illustrated and proposed in the conceptual framework, the risk assessment and risk treatment process are ideally to be embedded during this stage. This is supported by APM (2010), Chapman \& Ward (2003) and PMI (2017), stating that risk planning, identification, assessment and treatment should happen during this PLC planning stage. The risk identification step is to produce a complete rundown of risks in light of those occasions that may; make, upgrade, anticipate, corrupt, quicken or defer the accomplishment of goals. Next, risk analysis steps; both quantitative and qualitative analysis (if required) are to be put in place where thought of the causes and source of risks, their positive and negative impact and the probability that those outcomes can happen. This provides an input to the next step which is the risk evaluation development which includes contrasting the level of risk found amid the investigation procedures with risk criteria set up when the setting was considered (BS 31100:2011, 2011; IEC/FDIS 31010:2009(E), 2009; ISO/TR 31004:2013(E), 2013; MS ISO 31000:2010, 2010).

During the risk treatment process, choosing one or more options to modify the risks occurrences or consequences are to be implemented. Upon completion of risk treatment plan, implement risk treatment performed subsequently and throughout the project PLC. Implementing risk treatment focuses on ensuring that strategic plans are changed to reflect all earlier risk management, and this is fully reflected in any related project-sanction process and associated arrangements (APM, 2010). Implement risk treatment step starting at the end of the first complete cycle, getting on with changes to strategic plans and associated arrangements as soon as possible once it is clear what has to be done and appropriate approvals are in place (APM, 2010).

Project information from PLC planning phase comprise of project management plan, project documents, agreements, procurement documentation, enterprise environmental factors and organizational process assets will be inputted to risk assessment, risk treatment and implement risk treatment steps, with targeted output of project documents updates, risk register, risk report, change requests and project management plan updates back to PLC planning phase. 
As illustrated in proposed conceptual framework, the RMP activities passes three complete cycle, each on different stage of PLC. Rather single linear line RMP adoption, this three complete cycle known as iterative (multiple-pass looping) structure of RMP', posit by APM (2010) and Chapman \& Ward (2003). Iterations involve revisiting or looping back to earlier phases to develop, refine, or reconsider aspects of the analysis undertaken to date. This contrast with single pass (linear) approach to RMP activities as it deems ineffective and inefficient as argued by (Chapman \& Ward, 2003). This iterative movement similar to PLC flow that is not necessary linear sequential all the time, but mostly will iterative or overlapping, according to BS 6079-1:2010 (2010) and PMI (2017). The first RMP cycle starts at earliest of PLC definition stage and to be complete at PLC planning stage. The second cycle start at PLC design stage, performed throughout three sub-stage period; concept, schematic and detail development. The third cycle starts at PLC procurement stage and complete no later than at the end of the stage. Establishing the context and implementation of risk treatment steps performed throughout PLC until handing over. Implement risk treatment after the three complete RMP cycle, knowingly tactical risk treatment implementation performed at initial of PLC construction stage and throughout PLC (APM, 2010).

Monitoring and review involves constant monitoring or surveillance on periodic or ad-hoc basis. The monitoring and reviewing involves risk management's effective and efficient controls, obtain further improvement during risk assessment, analysing and learning lessons from risk events, detecting changes in the external and internal context and identifying emerging risks. Risk monitoring and review also involves managing residual risk; that includes unidentified risk and retaining it (ISO Guide 73:2009, 2009) that emerged after the risk treatment process (MS ISO 31000:2010, 2010). All residual risks that emerges must be managed the same way by going through the RMP (Abd Karim, 2014; Mohamed et al., 2014), thus the process is continuous until the very end of PLC.

Reporting conducted as form of communication with stakeholders (internal and external) that provide current RMP information (ISO Guide 73:2009, 2009). RMP should be traceable and its records provide the foundation for improvement in methods and tools, as well as in the overall process. The recorded input to be reported at the end of PLC handing over stage; contribute to the audit of the organization risk management framework in each project completion (MS ISO 31000:2010, 2010).

\section{CONCLUSION}

Theoretically, the research commits to enhance the landscape architecture body of knowledge through developing strategies to integrate RMP into PLC. The conceptual framework is developed based on the reviews of several studies covering two areas namely MS ISO31000:2010 RMP and landscape PLC. The developed hypothetical framework should be put into test in order to be amended and further exploring its reliability as well as potentiality. Future study would help to test the whole framework externally thus determining its suitability and ability to be implemented by the practitioners in validating this framework constructive benefits to the industry.

This conceptual framework development attempts to produce a hypothetical framework for landscape project risk management implementation. It will help enhance the understanding and application of risk management among landscape professionals for managing risk in landscape development in Malaysia. Practically, landscape project risk owner will be able to refer to the framework to integrate RMP systematically into landscape PLC effectively. This proactive landscape project management enables more feasible and accurate decision making in managing risks by landscape project practitioners to enhance project performance on top of reducing project issues. This will safeguard project practitioners from the impact of project issues and enhance landscape project in Malaysia environment and subsequently improve the built environment as well as contributing towards the country's landscape aspiration. 


\section{REFERENCES}

Abd Karim, S. B. (2014). The Development of an Empirical-Based Framework for Project Risk Management. University of Manchester.

Abdul-Rahman, H., Wang, C., \& Sheik Mohamad, F. (2015). Implementation of Risk Management in Malaysian Construction Industry: Case Studies. Journal of Construction Engineering, 2015(192742), 6. http://doi.org/10.1155/2015/192742

Abdul Malek, N., \& Mariapan, M. (2009). Visitors' perception on vandalism and safety issues in a Malaysian urban park. Theoretical and Empirical Researches in Urban Management, 4(13), 93-107.

Adnan, H. (2008). An Assessment of Risk Management in Joint Venture Projects ( JV ) in Malaysia. Asian Social Science, 4(6), 99-106. Retrieved from www.ccsenet.org/journal.html

Akintoye, A. S., \& MacLeod, M. J. (1997). Risk Analysis and Management in Construction. International Journal of Project Management, 15(1), 31-38. http://doi.org/http://dx.doi.org/10.1016/S0263-7863(96)00035-X

Algahtany, M., Alhammadi, Y., \& Kashiwagi, D. (2016). Introducing a New Risk Management Model to the Saudi Arabian Construction Industry. Procedia Engineering, 145(480), 940-947. http://doi.org/10.1016/j.proeng.2016.04.122

Antrop, M. (2005). Why Landscapes of the Past Are Important For the Future. Landscape and Urban Planning, 70(1-2), 21-34. http://doi.org/10.1016/j.landurbplan.2003.10.002

APM. (2010). Project Risk Analysis and Management Guide. (APM Risk Management Specific Interest Group, Ed.) (2nd ed.). Buckinghamshire: Association for Project Management.

APM. (2012). APM Body of Knowledge (6th ed.). Buckinghamshire: Association for Project Management. http://doi.org/10.1080/10894160.2010.508411

Bennet, L. F. (2003). The Management of Construction: A Project Lifecycle Approach. Oxford: Butterworth Heinneman.

BS 31100:2011. (2011). Risk management - Code of practice and guidance for the implementation of BS ISO 31000 (2nd ed.). London W4 4AL: British Standard. http://doi.org/10.1007/SpringerReference_2887

BS 6079-1:2010. (2010). Project Management - Part 1: Principles And Guidelines For The Management Of Projects. (British Standards Institution (BSI), Ed.) (3rd ed.). London W4 4AL: British Standards Institution (BSI). Retrieved from www.bsi- group.com/standards

BS ISO 31000:2009. (2009). Risk management - Principles and guidelines. (Technical Committee RM/1 Risk management, Ed.), British Standard (1st ed.). Geneva 20: British Standard. http://doi.org/10.1080/08982112.2013.814508

Capouya, L., Compton, K., Dantzler, V., \& Howard, L. (2012). Small Firm, Big Risk:Managing Relationships, Resources and Risk in the New Economy. In ASLA 2012 Annual Meeting and EXPO (pp. 1-10).

CEP-CDPATEP. (2011). Management Of The Territory: Landscape Management As A Process. (J. B. Fàbregas \& A. C. Ramos, Eds.), 6th Council of Europe Conference on the European Landscape Convention. Strasbourg: Council of Europe.

Chapman, C., \& Ward, S. (2003). Project Risk Management - Processes, Techniques and Insights (2nd ed.). West Sussex PO19 8SQ: John Wiley \& Sons Ltd. Retrieved from http://elib.ntt.edu.vn/ 
Cooper, D. F., Grey, S., Raymond, G., \& Walker, P. (2005). Project Risk Management Guidelines - Managing Risk in Large Projects and Complex Procurements. (B. C. International, Ed.). West Sussex PO19 8SQ: John Wiley \& Sons Ltd. Retrieved from www.wileyeurope.com

De Oliveira, U. R., Marins, F. A. S., Rocha, H. M., \& Salomon, V. A. P. (2017). The ISO 31000 Standard in Supply Chain Risk Management. Journal of Cleaner Production, 151, 616-633. http://doi.org/10.1016/j.jclepro.2017.03.054

Gilmartin, W. (2016). Four Principals Talk About Risk Management. Landscape Architecture Magazine - ASLA, October, 86-94. Retrieved from https://landscapearchitecturemagazine.org/current-issue/october-2016/

Godi, D. H., \& Sibelius, T. D. (2012). Project Risk Management: New Obstacles to Consider. In ASLA Annual Meeting Presentation (pp. 1-5). Phoenix Convention Center: American Society Of Landscape Architects (ASLA). Retrieved from www.asla.org/uploadedFiles/CMS/Meetings

Goh, C. S., \& Abdul-Rahman, H. (2013). The Identification and Management of Major Risks in Malaysian Construction Indusrty. Journal of Construction in Developing Countries, 18(1), 19-32.

Gould, F., \& Joyce, N. (2009). Construction Project Management. Pearson Prentice Hall.

Gray, C., \& Hughes, W. (2001). Building design management. Practice. Butterworth-Heinemann.

Hackett, M., Robinson, I., \& Statham, G. (2007). The Aqua Group of Procurement, Tendering and Contract Administration. Blackwell Publishing.

Hamzah Abdul-Rahman, Chen Wang, and F. S. (2015). Implementation of Risk Management in Malaysian Construction Industry: Case Studies. Journal of Construction Engineering, 3(1), 7. http://doi.org/10.1155/2015/192742

HB 436:2004. (2005). Risk Management Guidelines Companion to AS/NZS 4360:2004. (S. A. N. Zealand, Ed.). Sydney, NSW: Standards Australia International Ltd. http://doi.org/10.1016/B978-075067555-0/50157-2

Hillson, D. (2012). Project Risk Management: Past, Present And Future Views From The Chair. (Project Risk Management Specific Interest Group (APM Risk SIG), Ed.). Association for Project Management (APM).

Hillson, D., Grimaldi, S., \& Rafele, C. (2006). Managing Project Risks Using a Cross Risk Breakdown Matrix. Risk Management, 8(1), 61-76. http://doi.org/10.1057/palgrave.rm.8250004

Holmes, D. (2017). Stages of a Landscape Architecture Design project. Retrieved from http://worldlandscapearchitect.com/practice-stages-of-a-landscape-architecture-designproject/\#.WttBV9PwaRs

Hussain, N. H. M., \& Byrd, H. (2012). Towards a Compatible Landscape in Malaysia: An Idea, Challenge and Imperatives. Procedia - Social and Behavioral Sciences, 35(December 2011), $275-283$. http://doi.org/10.1016/j.sbspro.2012.02.089

Hussein, M. K. (2014). Users' perception towards selected recreational forest landscape maintenance in Selangor Darul Ehsan, Malaysia. Pertanika Journal of Social Science and Humanities, 22(4), 969-983. Retrieved from http://www.pertanika.upm.edu.my

Ibrahim, R. (2016). Towards A Sustainable Landscape of Urban Parks in Kuala Lumpur, Malaysia: A Study from a Management Perspective. University of Sheffield.

Ibrahim, R., Rahman, N. A., \& Tahir, O. M. (2009). Developing a Soft-Scape Standard for Improving the Landscape Quality in Malaysia. Alam Cipta, 4(EDB), 29-36. http://doi.org/ISSN1823-7231 
IEC/FDIS 31010:2009(E). (2009). Risk management - Risk Assessment Techniques. (International Electrotechnical Commission, Ed.), International Electrotechnical Commission. International Organization for Standardization (ISO).

ISO/TR 31004:2013(E). (2013). Risk management - Guidance for the implementation of ISO 31000 (Vol. TR 2013-10). Geneva 20. Retrieved from www.iso.org

ISO Guide 73:2009. (2009). Risk management - Vocabulary. Geneva 20: International Organization for Standardization (ISO). Retrieved from https://www.iso.org/obp/ui/\#iso:std:iso:guide:73:ed-1:v1:en

Jansson, M., \& Lindgren, T. (2012). A Review of the Concept 'Management' In Relation To Urban Landscapes and Green Spaces: Toward A Holistic Understanding. Urban Forestry and Urban Greening, 11, $139-145$. http://doi.org/10.1016/j.ufug.2012.01.004

Jusoff, K., Rashid, Z. A., \& Adnan, H. (2008). Legal Framework on Risk Management for Design Works in Malaysia. Journal of Politics and Law, 1(2), 26-32. http://doi.org/10.5539/jpl.v1n2p26

Jusoff, K., Yusuwan, N. M., Adnan, H., \& Omar, A. F. (2008). Clients' Perspectives of Risk Management Practice in Malaysian Construction Industry. Journal Politic and Law, 1(3), 121-130. http://doi.org/10.5539/jpl.v1n3p121

Kang, B. G., Fazlie, M. A., Goh, B. H., Song, M. K., \& Zhang, C. (2015). Current Practice of Risk Management in the Malaysia Construction Industry - The Process and Tools/Techniques. International Journal of Structural and Civil Engineering Research, 4(4), 371-377. http://doi.org/10.18178/ijscer.4.4.371-377

Kerzner, H. (2009). Project management: a systems approach to planning, scheduling, and controlling. New York. http://doi.org/10.1016/0377-2217(82)90164-3

Lester, E. I. A. (2003). Project Planning and Control (4th ed.). Burlington MA: Elsevier Butterworth-Heinemann. Retrieved from http://www.elsevier.com

Levy, S. M. (2010). Construction Process Planning and Management: An Owners' Guide to Successful. Oxford: Butterworth Heinneman.

Merriam, S. B. (2009). Qualitative Research: A Guide to Design and Implementation. The JosseyBass higher and adult education series (Vol. 2nd). http://doi.org/10.1097/NCI.0b013e3181edd9b1

Mills, A. (2007). A Systematic Approach to Risk Management for Construction. Structural Survey, 19(5), 245252. http://doi.org/10.1108/02630800110412615

Mohamed, O., Abd-Karim, S. B., Roslan, N. H., Mohd Danuri, M. S., \& Zakaria, N. (2014). Risk management: Looming the modus operandi among construction contractors in Malaysia. International Journal of Construction Management, 15(1), 82-93. http://doi.org/10.1080/15623599.2014.967928

MS ISO 31000:2010. (2010). Risk Management - Principles and Guidelines (ISO 31000:2009, IDT). (I. S. C. on O. M. (ISCO), Ed.). Cyberjaya: Department of Standards Malaysia. Retrieved from http://www.standardsmalaysia.gov.my

$\mathrm{Ng}$, A., \& Loosemore, M. (2007). Risk allocation in the private provision of public infrastructure. International Journal of Project Management, 25(1), 66-76. http://doi.org/10.1016/j.ijproman.2006.06.005

Osman Mohd Tahir. (2005). Urban Landscape Management in Malaysia:In search of a Sustainable Management System. University of Newcastle.

PMI. (2017). A Guide To The Project Management Body Of Knowledge (PMBOK Guide). (PMBOK, Ed.) (6th ed.). Newton Square, PA: Project Management Institute, Inc. http://doi.org/10.1002/pmj.21345 
Prieto Ibáñez, A. J., Macías Bernal, J. M., Chávez de Diego, M. J., \& Alejandre Sánchez, F. J. (2016). Expert System for Predicting Buildings Service Life under ISO 31000 Standard. Application in Architectural Heritage. Journal of Cultural Heritage, 18, 209-218. http://doi.org/10.1016/j.culher.2015.10.006

Purdy, G. (2010). ISO 31000:2009 - Setting a New Standard for Risk Management. Risk Analysis, 30(6), 881-886. http://doi.org/10.1111/j.1539-6924.2010.01442.x

Sekaran, U. (2003). Research Methods For Business A Skill Building Approach. John Wiley \& Sons, Inc. http://doi.org/10.1007/s13398-014-0173-7.2

Sousa, V., Almeida, N. M. De, \& Dias, L. A. (2012). Risk Management Framework for the Construction Industry According to the ISO 31000:2009 Standard. Journal of Risk Analysis and Crisis Response, 2(4), 261-274. http://doi.org/10.1111/j.1539-6924.2010.01442.x

Turner, J. R. (2009). The Handbook of Project Based Management: Leading Strategic Change in Organizations. Manager (Vol. 3). McGraw Hill.

Ward, S., \& Chapman, C. (2003). Transforming project risk management into project uncertainty management. International Journal of Project Management, 21(2), 97-105. http://doi.org/10.1016/S0263-7863(01)000801

Zubir, Z. (2015). Project Management, Maintenance And Supervision. Kursus Amalan Ikhtisas Arkitek Landskap (KAIAL) 2015. Serdang: Institute of Landscape Architects Malaysia (ILAM). 